\title{
Mathematical Modeling in Rehabilitation of Cleft Lip and Palate
}

\author{
Martha R. Ortiz-Posadas ${ }^{1}$ and Leticia Vega-Alvarado ${ }^{2}$ \\ ${ }^{1}$ Electrical Engineering Department. Universidad Autónoma Metropolitana-Iztapalapa \\ ${ }^{2}$ Centro de Ciencias Aplicadas y Desarrollo Tecnológico \\ Universidad Nacional Autónoma de México \\ México
}

\section{Introduction}

Mathematical modeling is the art of translating problems from an application area into tractable mathematical formulations whose theoretical and numerical analysis provides insight, answers, and guidance useful for the originating application. In recent years, mathematicians and medical researchers have combined their individual expertise to study diseases of the human body that are amenable to mathematical analysis. Mathematical models have been proposed in many areas of medicine. Indeed, mathematical modeling in medicine can exist at many scales from cellular processes to the delivery of healthcare. In specific, the importance of discovering the response of a patient to a determined treatment as a feedback for professionals in health care, since it allows them to determine the evolution of the prescribed therapeutics and, where appropriate, to continue or modify treatment.

For patients with cleft lip and palate, it is of great use to have available new models allowing the description of the initial and final condition of them. With this information it is possible to evaluate the evolution of their rehabilitation, which is a process that depends on patient's growth and development, it is a process that depends on time. These patients must be attended by a group of specialists from different areas such as surgery, orthodontics, psychology and speech therapy that form a multidisciplinary cleft lip and palate team, whose objective is to integrally rehabilitate the patients and lead them to normal biopsychosocial conditions.

For developing a mathematical model of this clinical problem, we selected the logical combinatorial approach of pattern recognition theory which uses analogies (likelihood, similarity, etc.) between the objects (patients). The analogy concept is a fundamental methodological tool to be able to establish the relations between the objects and hence the likelihood that exist among them. The mathematical modeling involves the process of variable selection (which yields a description of the objects under study) and the knowledge of their relative importance (the one such variables have in this case). For this reason, we had to define the variables and their domains, the comparison criteria for each variable and an analogy function, which allows quantifying the similarity between patients (cleft descriptions). Finally we used a partial precedence algorithm called voting 
algorithm to classify patients under study. The work was developed in a joint collaboration with the multidisciplinary team for cleft lip and palate at the Tacubaya Pediatrics Hospital, which belongs to the Health Institute in Mexico City. The method was tested with a sample of 95 patients cared for by this team at the Reconstructive Surgery Service from this Hospital.

\section{The clinical problem: Congenital malformation in the lip and/or palate}

The clinical problem consists of congenital malformations in the lip and/or palate, which are called cleft-primary palate and/or cleft-secondary palate respectively. Primary palate is formed by the prolabium, the premaxilla, and columella (Kernahan \& Stark, 1958). This is the visible part of these kinds of malformations. The secondary palate begins at the incisive foramen and extends posteriorly (Fig. 1). It includes the horizontal portion of the premaxilla, horizontal portion of the palatine bones, and soft palate (Kernahan \& Stark, 1958). It is important to say that cleft of the primary palate can be present in a unilateral way, left or right, or in a bilateral way (Fig. 2). The latter is formed from the combination of two unilateral fissures. Worldwide incidence of these congenital abnormalities is around one per 500-700 of all births; the birth prevalence rate varies substantially across ethnic groups and geographical areas (WHO, 2007). For example, in the USA the prevalence is 6.35/10,000 live births for cleft palate only and 10.63/10,000 live births for cleft lip with or without cleft palate (Parker et al, 2010). In Mexico it is 0.81 per 1000 live born babies (Health Ministry of Mexico, 2008), meaning more than 90000 cases in this country.

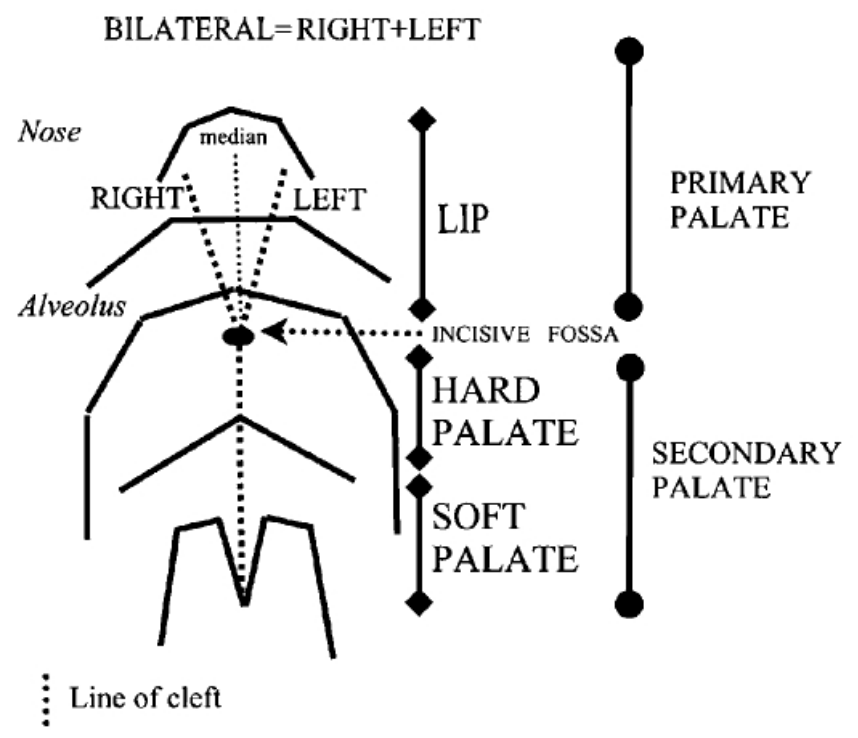

Fig. 1. Schematic representation of the lip and palate (Hodgkinson et al, 2005) 


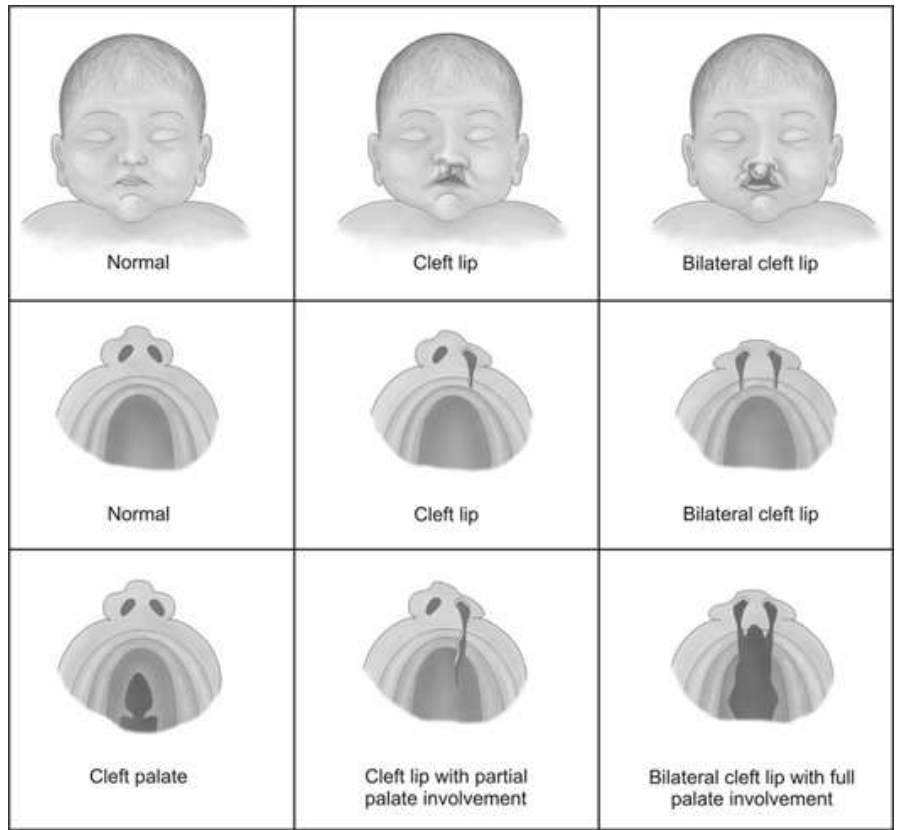

Fig. 2. Cleft lip and palate (unilateral and bilateral) (Children’s Hospital of Wisconsin, 2009)

\section{Cleft palate clinical team}

The management of patients with cleft lip and palate presents many challenges but also many rewards. In order to do an integral rehabilitation, patients are treated by a multidisciplinary cleft lip and palate team. This is a group of individuals from different specialist backgrounds who work closely together, not only to bring each specialist's particular expertise to the patient in the optimum way, but also to develop an understanding of the requirements and specialist skills of the other team members to enhance the delivery of the total package (Hodgkinson et al, 2005; Sze-Van et al, 2007). The multidisciplinary team encompassing four medical specialties: reconstructive surgery, orthodontics, speech therapy and psychology. These four specialties are described below.

\subsection{Reconstructive surgery}

Reconstructive surgery is performed on abnormal structures of the body caused by congenital defects, developmental abnormalities, trauma, infection, tumors or disease. It is generally performed to improve functions, but may also be done to approximate a normal appearance. Reconstructive surgery is generally covered by most health insurance policies, although coverage for specific procedures and levels of coverage may vary greatly. In facial surgeries, these can be performed to correct facial defects such as cleft lip, breathing problems, or chronic infections, such as those that affect the sinuses, or even snoring.

Closure of the cleft in the lip and palate requires a surgical procedure. There are a variety of surgical techniques and timings. Any surgical protocol has to satisfy several apparently 
contradictory requirements: 1) Cosmetic restoration of a normal appearance to the patient at an appropriate time. 2) Functional restoration of the lip and particularly the palate to provide normal eating and drinking, and produce a functionally adequate palate to allow the development of normal speech. 3) Optimum facial growth and development to prevent deformity developing in association with impaired growth.

Surgical closure of a cleft lip is performed as early in infancy as is compatible with a good long-term result; the contemporary consensus being 10 to 12 weeks of age. Correcting the lip earlier than this (immediately after birth) offers psychological advantages to the family and was briefly popular in the 1960s. However, it entails a greater risk of surgical morbidity and maxillary growth retardation, and the long-term esthetic results tend not to be unsatisfactory. Moreover, after 10 to 12 weeks other problems are more likely to be identified (if they exist), and the immune system is better developed to cope with infection (Witzel MA et al, 1984).

\subsection{Ortodonthics}

Orthodontic treatment (alignment of the teeth and their underlying supporting structures) can be used to intervene at almost any age from birth to teenage years, but the orthodontic cleft specialist must be cognizant of the burden of care for these patients. Examination of facial balance and proportions is essential in determining a treatment plan that combines surgery and orthodontics (Friede H et al, 1986; Semb G, 1991). Figure 3 shows some measures that are considered for orthodontic treatment. Primary surgery for cleft lip and palate is only the beginning of management for this condition; any congenital malformation and scars of corrective surgery during infancy affect physiological development of the skeleton and soft tissues, which gives rise to varying degrees of maxillary underdevelopment. The degree of maxillomandibular discrepancy determines the ultimate treatment plan. If the skeletal discrepancy is mild and esthetic concerns are minimal, dental compensation by orthodontic treatment alone may resolve the malocclusion. Alterations in the axial inclination of the teeth may adequately camouflage the skeletal relationship. In cases where the skeletal discrepancy is beyond the envelope of orthodontic camouflage or when an individual is suspected to outgrow the dental correction, orthognathic surgery may eventually become necessary to achieve normal occlusion. The most frequent skeletal malformations in secondary palate are hypoplasia and malposition in the three planes of the superior maxilla space. In these cases, combined orthodontic and surgical treatment is necessary (Keer WJ et al, 1992; Stellzig - Eisenhauer A et al, 2002 ).

\subsection{Speech therapy}

Children born with cleft lip and cleft palate may have problems in developing speech and language skills. It was reported that $25 \%$ developed normal speech spontaneously and $75 \%$ required episodes of speech and language therapy (Witzel, 1991). After cleft palate repair, all patients are referred to the speech therapists for speech evaluation. The speech and language therapists will evaluate the patient's ability to understand and use language and his speech resonance (oral and nasal tone quality). Most children with cleft lip and/or palate are slower in developing consonant sounds and in learning to talk. Speech therapy entails: teaching blowing skills, maintaining intraoral pressure, foster muscle training, stimulating speech development and the prevention of undesirable compensatory articulations. Formal training starts around 2 to 3 years of age. 


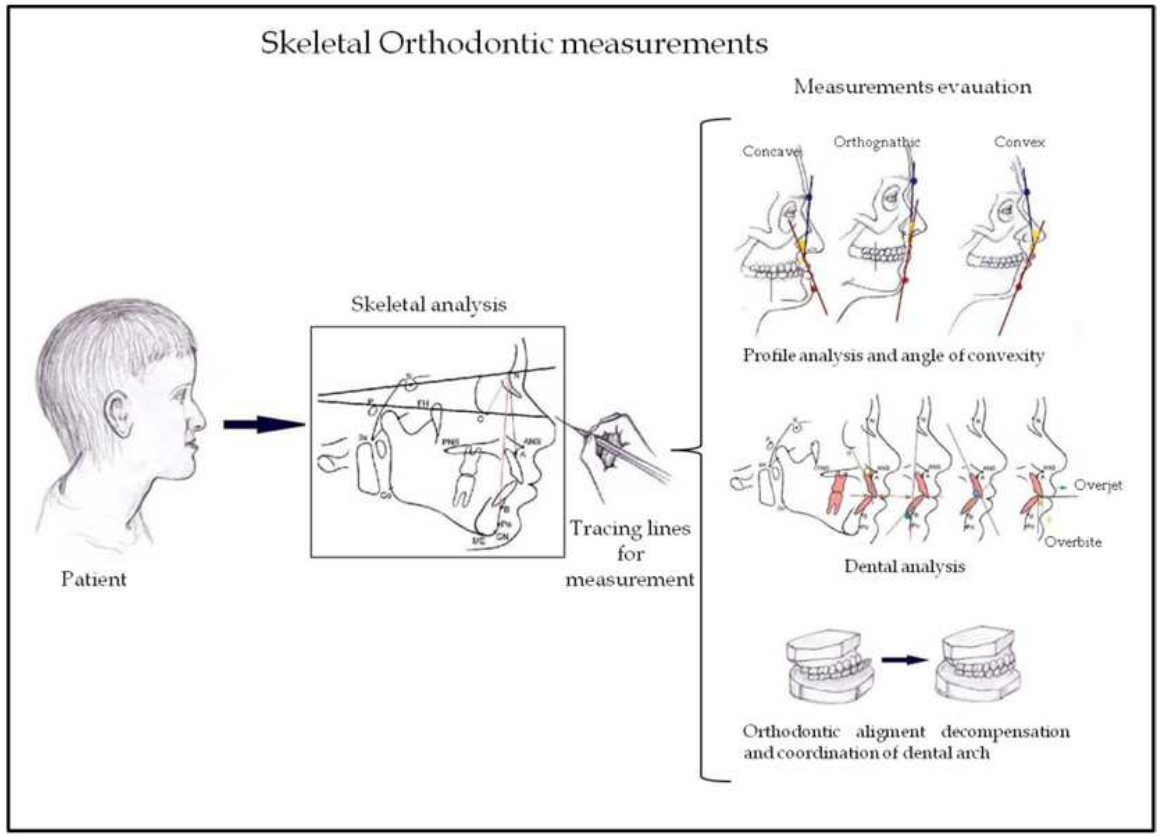

Fig. 3. An overview of orthodontic evaluation.

The speech and language therapist with the cleft team will contribute to assessment, diagnosis and treatment planning for children requiring further surgery for velopharyngeal insufficiency affecting speech outcome and symptomatic palatal fistulae. In addition, assessment is required for older children and adults who require maxillary advancement and those needing prosthetic management of velopharyngeal insufficiency where surgery is contraindicated (Fox VA et al, 2002).

\subsection{Psychology}

Parents are often very shocked when they learn their child has a facial disfigurement. They need reassurance, support and time to assimilate the information. In this sense, the psychological care of the patient with a cleft begins at the time of diagnosis, even if this is before birth. With more involvement of specialist psychologists within cleft teams the importance of this is becoming increasingly apparent.

Taking a lifespan perspective, the earliest interventions that may help to improve social competence and reduce distress begin in the perinatal stages of care when working with parents and significant family members. The next stage of opportunities for interventions arises as the child begins to function within the family and within external systems such as school and peer groups. As the child matures and faces the task of individuation from the family, there may be a need for psychological work. Lastly, adulthood provides its own set of challenges to the individual and there is potential for further psychological interventions throughout this period of life. While some of the psychological needs of patients and their families will require the knowledge and expertise of a clinical psychologist, many needs can be met by ensuring psychological thinking and planning takes place at all levels of care. 
Although there has been an assumption that parents find it harder to bond with a baby with a facial disfigurement (Pruzinsky T, 1992; Langlois J, 1995), there is growing evidence that babies born with a cleft are not at particular risk of developing an insecure attachment (Coy $\mathrm{K}$ et al, 2002; Pelchat $\mathrm{D}$ et al, 2003). Indeed, forming a secure attachment to the parent may be one of the factors that helps buffer the child with a cleft. Hence it is the role of the cleft lip and palate team to try to facilitate secure infant attachments.

\section{Introduction to the logical-combinatorial approach}

In order to develop a mathematical model of this clinical problem, we selected the logical combinatorial approach of pattern recognition (Martínez-Trinidad \& Guzman-Arenas, 2001). This approach works with the descriptions of the objects in terms of a combination of quantitative and qualitative variables. Variables can be processed by numeric functions in a differential manner, depending on their nature. Furthermore, it gives the possibility of "absent information" in some feature values in the objects descriptions. For classifying objects, there are several classification algorithms based on the concept of partial precedence, that is, partial analogies: an object can be alike to another object not in its totality. Those parts which do alike each other, can give information about possible regularities; of course not all of the same magnitude. These characteristics are suitable to model classification problems in medicine and that is why we selected this approach. The mathematical model is described below.

\subsection{Mathematical model}

Let $\mathbf{U}$ be a universe of objects, and let us consider a given finite sample $\mathbf{O}=\{\mathrm{O} 1, \ldots, \mathrm{Om}\}$ of such (descriptions of the) objects. We shall denote by $X=\left\{x_{1}, \ldots, x_{n}\right\}$ the set of features or variables used to study these objects. Each of these variables has associated a set of admissible values (its domain) $\mathrm{M}_{\mathrm{i}}=\left\{\mathrm{m}_{\mathrm{i} 1}, \mathrm{~m}_{\mathrm{i} 2}, \ldots\right\} \cup\{*\}$. Over $\mathrm{M}_{\mathrm{i}}$ no algebraic, topologic or logic structure is assumed. These sets of values, in contrast to the other approaches, can be of any nature: variables can be quantitative and qualitative simultaneously. Each of these sets also contains a special symbol $\left(^{*}\right)$ denoting absence of information (missing data). Thus, incomplete information about some objects is allowed. This will turn out to be a fundamental feature of this pattern recognition paradigm. By a description of an object $\mathrm{O}$ we understand an n-tuple $\mathrm{I}(\mathrm{O})=\left(\mathrm{x}_{1}(\mathrm{O}), \ldots, \mathrm{x}_{\mathrm{n}}(\mathrm{O})\right)$.

Let $C=\left\{C_{1}, \ldots, C_{n}\right\}$ be a set of functions called comparison criteria for each variable $x_{i} \in X$ defined as the Cartesian product of variable domain such as: $C_{i}: M_{i} \times M_{i} \rightarrow \Delta_{i} ; i=1, \ldots, n$ where $\Delta_{\mathrm{i}}$ can be of any nature; it is an ordered set and can be finite or infinite. Comparison criteria can denote similarity or difference between two different values of the same variable $\mathrm{x}_{\mathrm{i}}$. The characteristics of each comparison criterion $\left(\mathrm{C}_{\mathrm{i}}\right)$ depend on the problem that has been modeled. However, it is important to remark that every $C_{i}$ is designed individually to reflect the nature and interpretation of each feature $x_{i}$. In this sense, the set $\mathbf{C}$ allows differentiation and non-uniform treatment of the features that describe the objects. Furthermore, it gives also the possibility of "absent information" in some feature values in the objects descriptions. It is important to mention that all comparison criteria must be defined jointly with the expert in order to incorporate his/her expertise in the problem modeling. In the context of medicine problems, the experts will be the physicians, surgeons, etc. with their 
knowledge and expertise, with the ability to provide the entire criterion about medical problem modeling (Martínez-Trinidad \& Guzman-Arenas, 2001).

In general, medical problems imply a supervised classification problem, which consists in to recognize, given a set of objects grouped into classes, in which one (or more than one) of these classes, new objects belong. In this kind of problems, we assume that the universe $\mathbf{U}$ is structured in a finite number $\mathrm{K}_{1}, \ldots, \mathrm{K}_{\mathrm{r}}$ of proper subsets, called classes, and from each of them we have a sample of descriptions of objects, the so-called training matrix $T M=\left\{K_{1} \cup \ldots\right.$ $\cup \mathrm{K}_{\mathrm{r}}$ \}. The problem is to find the membership relations from a new object from $\mathbf{U}$ (outside the given samples) with the $\mathrm{r}$ classes. This relationship does not have to be all or nothing.

The logical combinatorial approach deals with spaces without algebraic (or of any other kind of) structure. The representation space is simply a Cartesian product, which also has the peculiarity of being heterogeneous, that is, each of the sets forming it can be of different nature: a set of real numbers, a set of labels, a set of truth values from a given logic, etc. An example of this appears in medical diagnosis problems, where descriptions take the form $\mathrm{I}(\mathrm{O})=\left(\right.$ black, female, $45,38.63,1500,{ }^{*}$, slight, 2$)$, where * means absence of information. That is, objects are described in terms of qualitative and quantitative variables. Thus, the tools herein presented. Most significant algorithms of supervised classification in the logical combinatorial approach are those works based on partial precedence. As follows we describe the voting algorithm.

\subsubsection{Voting algorithm}

This algorithm comprising six steps: (1) defining the system of support sets; (2) defining the similarity function; (3) row evaluation, given a fixed support set; (4) class evaluation for a fixed support set; (5) class evaluation for all the system of support sets, and (6) resolution rule. Thus, to define a voting algorithm, is to define a set of parameters for each of the above six steps.

A support set is a non-empty subset $\omega=\left\{x_{i 1}, \ldots, x_{i s}\right\}$ of features which shall be used to analyze the objects. We denote as $\omega \mathrm{O}$ the sub-description in terms of the features of $\omega$. Thus, a system of support sets denoted by $\Omega$ are several support sets which together will allow analysis of the objects to be classified, comparing them with objects in each one of the classes $K_{i}, i=1, \ldots, r$. Note that said analysis is done paying attention to different parts or sub-descriptions of the objects, and not analyzing the complete descriptions. Examples of systems of support sets are combinations of variables with a fixed cardinality, the power set of features, etc.

The analogy between two objects is formalized by means of the concept of similarity function $\beta$. This function is based on the comparison criterion $C_{i}$ generated for each variable $\mathrm{x}_{\mathrm{i}}$. It is important to mention that the similarity function can evaluate the similarity or difference between two objects, i.e., between their descriptions. $\beta\left(\mathrm{I}(\mathrm{Oi}), \mathrm{I}\left(\mathrm{O}_{\mathrm{j}}\right)\right)$ is defined by:

$$
\beta\left(\left(\mathrm{C}_{1}\left(x_{1}\left(\mathrm{O}_{\mathrm{i}}\right), x_{1}\left(\mathrm{O}_{\mathrm{j}}\right)\right), \ldots, \mathrm{C}_{\mathrm{n}}\left(x_{n}\left(\mathrm{O}_{\mathrm{i}}\right), x_{n}\left(\mathrm{O}_{\mathrm{j}}\right)\right)\right)\right)
$$

Let $\beta_{\omega}$ be a partial similarity function defined by: $\beta_{\omega}\left(\mathrm{I}\left(\mathrm{O}_{\mathrm{i}}\right), \mathrm{I}(\mathrm{O})\right)=\sum_{x_{t} \in \omega} \rho_{t} C_{t}\left(x_{t}\left(O_{i}\right), x_{t}(O)\right)$, where $\omega$ represents a support set and $\rho_{t}$ is the relevance parameter associated to each variable $x_{t}$ defined by the expert. 
When the systems of support sets and the similarity function have been defined, the voting process starts in the stage of row evaluation; that is, the similarity between the different parts (support sets) of the objects already classified and those to be classified is analyzed. Each row of TM (each object $\mathrm{O}_{i} \in \mathrm{TM}$ ) is compared with object $\mathrm{O}$ to be classified using the partial similarity function $\beta \omega$. This evaluation is a function of the similarity values among the different parts (support set) being compared. An example of this evaluation is:

$$
\Gamma_{\omega}\left(\mathrm{O}_{i}, \mathrm{O}\right)=\rho\left(\mathrm{O}_{i}\right) \rho(\omega) \beta\left(\omega \mathrm{I}\left(\mathrm{O}_{i}\right), \omega \mathrm{I}(\mathrm{O})\right)
$$

Where $\rho(\mathrm{Oi})$ is the weight of the object Oi from TM, $\rho(\omega)$ is the weight of the support set $\omega$ and $\beta(\omega \mathrm{I}(\mathrm{Op}), \omega \mathrm{I}(\mathrm{O}))$ is the similarity value of the compared objects.

The class evaluation for a fixed support set $\omega$ consists in totaling the evaluations obtained for each of the objects TA with respect to the object $\mathrm{O}$ to be classified. This total evaluation is a function of the row evaluations already obtained. An example of this evaluation is:

$\Gamma_{\omega}^{j}(O)=\frac{1}{\left|K_{j}\right|} \sum_{t=1, \ldots,\left|K_{j}\right|} \Gamma_{\omega}\left(O_{i}, O\right)$. The upper index refers to the class $\mathrm{K}_{\mathrm{j}}$.

In class evaluation for all the system of support sets, evaluations are totaled for all the system of support sets. Following our example, this step could be expressed as follows:

$$
\Gamma_{j}(O)=\frac{1}{|\Omega|} \sum_{\omega \in \Omega} \Gamma_{\omega}^{j}(O)
$$

Finally, the resolution rule is a function that establishes a criterion taking into account each voting thus obtained, and reaches a decision concerning the relations of the object to be classified with every class of the posed problem.

\section{Mathematical modeling of the clinical problem}

\subsection{Cleft lip and palate mathematical model}

\subsubsection{Variables and comparison criteria}

In order to describe the type of cleft it was necessary to define, in conjunction with the five surgeons team (with an expertise about 20 years in this clinical area), the variables related with the different anatomical structures affected (cleft, lip and nose). In this sense, eighteen variables were defined for cleft description. Comparison criterion for each variable was modeled and all are of difference. That is, the minimum value of its domain means that the compared values are equal (there is no difference), and the maximum value means that the compared values are different (Ortiz-Posadas et al, 2009).

Cleft. For describing cleft, two variables were defined,: 1) primary palate, and; 2) secondary palate. The variables $\left(\mathrm{x}_{\mathrm{i}}\right)$, their domain $\left(\mathrm{M}_{\mathrm{i}}\right)$ and the comparison criterion $\left(\mathrm{C}_{\mathrm{i}}\right)$ are shown in Table 1. These malformations can have different characteristics with a direct consequence on surgical complexity. For this reason it was necessary to assign a relevance parameter $(\rho)$ to the different clefts. For primary palate it was $\rho=0.65$ and for secondary palate $\rho=0.35$, this parameter clearly means that primary palate (the visible part) is more important than the second one. By the other hand, primary palate can take values into the interval $[0,100]$ and secondary palate into [0,55]. Likewise, comparison criteria were defined as the absolute 
difference of the compared values divided by 100 (or 55) depending on the considered variable. This division is done with the objective to limit the result into $[0,1]$.

\begin{tabular}{|c|c|c|c|}
\hline$x_{i}$ & $\rho_{\mathrm{i}}$ & $\mathrm{M}_{\mathrm{i}}$ & $C_{i}$ \\
\hline $\begin{array}{l}\mathrm{x}_{1} \text {. Primary } \\
\text { palate } \\
\text { (left and/or right) }\end{array}$ & $\begin{array}{c}0 \\
1 \\
3 \\
6 \\
12 \\
12\left(1+\mathrm{m} \times 10^{-1}\right) \\
(\mathrm{m}: \text { milimeters })\end{array}$ & $\begin{array}{l}\text { Normal } \\
\text { Microform } \\
\text { Incomplete } 1 / 3 \\
\text { Incomplete } 2 / 3 \\
\text { Complete with contact of segments } \\
\text { Complete without contact of segments }\end{array}$ & $C_{i}=\frac{|x-y|}{100}$ \\
\hline $\begin{array}{l}\mathrm{x}_{2} \text {. Secondary } \\
\text { palate } \\
\text { (left and/or right) }\end{array}$ & $\begin{array}{l}25 \\
27 \\
28 \\
34 \\
36 \\
37 \\
50 \\
53 \\
55\end{array}$ & $\begin{array}{l}\text { Normal } \\
\text { Submucous without bifid uvula } \\
\text { (soft palate) } \\
\text { Submucous with bifid uvula } \\
\text { (soft palate) } \\
\text { Incomplete } 1 / 3 \text { central (soft palate) } \\
\text { Incomplete } 2 / 3 \text { unilateral } \\
\text { (soft palate + one palatal shelf) } \\
\text { Incomplete } 2 / 3 \text { bilateral } \\
\text { (soft palate + both palatal shelves) } \\
\text { Complete grade I unilateral } \\
\text { Incomplete } 2 / 3+\text { Complete grade I } \\
\text { Complete grade I bilateral } \\
\text { Complete grade II unilateral } \\
\text { Incomplete } 2 / 3+\text { Complete grade II } \\
\text { Complete grade II bilateral } \\
\text { Complete grade III unilateral } \\
\text { Incomplete } 2 / 3+\text { Complete grade III } \\
\text { Complete grade III bilateral }\end{array}$ & $C_{i}=\frac{|x-y|}{55}$ \\
\hline
\end{tabular}

Table 1. Cleft variables, domain, relevance parameter and comparison criteria.

Lip. In this case 9 variables were defined. All these variables have the same 4 -valued domain: yes, almost (less than optimal), barely (more deficient) and no. Their comparison criterion are of the fuzzy type, with a homogeneous scale, or rather, the difference between two consecutive values is equivalent (according to the surgeons team), and it is represented by a comparison matrix (Table 2). Notice that this matrix displays two important characteristics: 1) The main diagonal is equal to zero because there is no difference when equal values are compared; and 2) this matrix is symmetric. By the other side, all the variables considered do not have the same importance for the surgeon. Hence informational importance (relevance) was assigned by a relevance parameter $\left(\rho_{i}\right)$ to each of them with the support of the clinical model, the specialist experience and the type of fissure. These variables are useful for evaluating the initial condition of the patient lip (before surgery), as well as after any surgical procedure. 


\begin{tabular}{|c|c|c|c|c|c|c|c|}
\hline$x_{i}$ & $\rho_{\mathrm{i}}$ & $\mathrm{M}_{\mathrm{i}}$ & & & $\mathrm{C}_{\mathrm{i}}$ & & \\
\hline $\mathrm{x}_{3}$. Symetry of lip height & 0.16 & & & & & & \\
\hline $\mathrm{x}_{4}$. Normal lip height & 0.15 & & & yes & almost & barely & no \\
\hline$x_{5}$. Muscular integrity & 0.14 & yes & yes & 0 & 0.33 & 0.66 & 1.0 \\
\hline$x_{6}$. Skin integrity & 0.15 & almost & almost & & 0 & 0.33 & 0.66 \\
\hline $\begin{array}{l}x_{7} . \text { Mucous membrane } \\
\text { integrity }\end{array}$ & 0.08 & barely & barely & & & 0 & 0.33 \\
\hline $\begin{array}{l}\mathrm{x}_{8} . \text { Symmetry of lip } \\
\text { thickness }\end{array}$ & 0.12 & no & no & & & & 0 \\
\hline $\begin{array}{l}\mathrm{x}_{9} \text {. Symmetry of philtral } \\
\text { ridges }\end{array}$ & 0.10 & & & & & & \\
\hline$x_{10}$. Normal sulcus depth & 0.05 & & & & & & \\
\hline $\begin{array}{l}\mathrm{x}_{11} \text {. Presence of cupid } \\
\text { arch }\end{array}$ & 0.05 & & & & & & \\
\hline
\end{tabular}

Table 2. Domain, comparison criteria and relevance parameter (r) for lip variables

Nose. In this case, seven variables with different domain were defined, as well as three different fuzzy comparison criteria (Table 3). In the same manner as in the lip, each criterion has a homogeneous scale and it is represented by a comparison matrix. These variables are useful for evaluating the initial condition of the patient nose, as well as after any surgical procedure

Variables of cleft-primary palate and cleft-secondary palate jointly with lip and nose variables define the initial space representation (ISR). With this set of variables it was possible to incorporate elements that are not considered in other approaches and allows to more fully describing the clefts.

\subsubsection{Similarity function for cleft palate}

This similarity function was defined taking into account the partial similarity related with the different structures considered in cleft evaluation. In this sense, three support sets were defined: the first, formed by the cleft variables set; the second, by the lip variables set, and the third, by the nose variables set.

Definition 1. Let $\Omega=\left\{\omega_{\text {cleft }}, \omega_{\text {lip }}, \omega_{\text {nose }}\right\}$ be the system of support sets for cleft lip and palate. Where $\omega_{\text {cleft }}=\left\{x_{1}, x_{2}\right\}, \omega_{\text {lip }}=\left\{x_{3}, \ldots, x_{11}\right\}$ and $\omega_{\text {nose }}=\left\{x_{12}, \ldots, x_{18}\right\}$.

Definition 2. Let $\beta_{\text {cleft }}$ the partial similarity function for cleft defined by:

$$
\beta_{\text {cleft }}\left(I\left(P_{i}\right), I\left(P_{j}\right)\right)=1-\sum_{t=1}^{2} \rho_{t} C_{t}\left(x_{t}\left(P_{i}\right), x_{t}\left(P_{j}\right)\right)
$$

Definition 3. Let $\beta_{\text {lip }}$ the partial similarity function for lip, defined by:

$$
\beta_{\text {lip }}\left(I\left(P_{i}\right), I\left(P_{j}\right)\right)=1-\sum_{t=3}^{11} \rho_{t} C_{t}\left(x_{t}\left(P_{i}\right), x_{t}\left(P_{j}\right)\right)
$$




\begin{tabular}{|c|c|c|c|c|c|c|c|}
\hline$x_{i}$ & $\rho_{\mathrm{i}}$ & $\mathrm{M}_{\mathrm{i}}$ & & & $\mathrm{C}_{\mathrm{i}}$ & & \\
\hline $\begin{array}{l}\mathrm{x}_{12 .} \text { Symmetry of nasal } \\
\text { floor }\end{array}$ & 0.17 & & & yes & almost & barely & no \\
\hline $\begin{array}{l}\mathrm{x}_{13} . \text { Symmetry of nostril } \\
\text { archs }\end{array}$ & 0.25 & yes & yes & 0 & 0.33 & 0.66 & 1 \\
\hline $\begin{array}{l}\mathrm{x}_{14 .} \text { Symmetry of notrils } \\
\text { (vertical plane) }\end{array}$ & 0.10 & almost & almost & & 0 & 0.33 & 0.66 \\
\hline $\begin{array}{l}\mathrm{x}_{15} \text { Symmetry of nostrils } \\
\text { (anteroposterior plane) }\end{array}$ & 0.10 & barely & barely & & & 0 & 0.33 \\
\hline $\begin{array}{l}\mathrm{x}_{16 .} \text { Nasal septum } \\
\text { deviation }\end{array}$ & 0.11 & no & no & & & & 0 \\
\hline \multirow{3}{*}{$\mathrm{x}_{17}$ Length of columella } & \multirow{3}{*}{0.15} & \multirow{3}{*}{$\begin{array}{c}\text { normal } \\
\text { almost } \\
\text { barely } \\
\text { absent }\end{array}$} & & norm & almost & barely & absent \\
\hline & & & $\begin{array}{l}\text { norm } \\
\text { almost } \\
\text { barely } \\
\text { absent }\end{array}$ & 0 & $\begin{array}{c}0.33 \\
0\end{array}$ & $\begin{array}{c}0.66 \\
0.33 \\
0\end{array}$ & $\begin{array}{c}1 \\
0.66 \\
0.33 \\
0 \\
\end{array}$ \\
\hline & & & & greater & normal & minor & \\
\hline$x_{18}$ Width of nasal base & 0.12 & $\begin{array}{c}\text { greater } \\
\text { normal } \\
\text { minor }\end{array}$ & $\begin{array}{c}\text { greater } \\
\text { normal } \\
\text { minor }\end{array}$ & 0 & $\begin{array}{c}0.5 \\
0\end{array}$ & $\begin{array}{c}1 \\
0.5 \\
0 \\
\end{array}$ & \\
\hline
\end{tabular}

Table 3. Lip variables, relevance parameter, domain and comparison criteria.

Definition 4 . Let $\beta_{\text {nose }}$ the partial similarity function for nose, defined by:

$$
\beta_{\text {nose }}\left(I\left(P_{i}\right), I\left(P_{j}\right)\right)=1-\sum_{t=1}^{7} \rho_{t} C_{t}\left(x_{t}\left(P_{i}\right), x_{t}\left(P_{j}\right)\right)
$$

Definition 5. Let $\beta_{T C}$ the total similarity function for cleft lip and palate, defined by:

$$
\beta_{T C}\left(I\left(P_{i}\right), I\left(P_{j}\right)\right)=\left(\begin{array}{c}
0.60\left[\beta_{\text {cleft }}\left(I\left(P_{i}\right), I\left(P_{j}\right)\right)\right]+ \\
+0.20\left[\beta_{\text {lip }}\left(I\left(P_{i}\right), I\left(P_{j}\right)\right)\right]+ \\
\quad+0.20\left[\beta_{\text {nose }}\left(I\left(P_{i}\right), I\left(P_{j}\right)\right)\right]
\end{array}\right)
$$

Where $\beta_{\text {cleft, }} \beta_{\text {lip }}, \beta_{\text {nose }}$ are the similarity functions corresponding to the affected structures cleft, lip and nose, with a relevance parameter of $0.60,0.20$ y 0.20 respectively.

\subsubsection{Evaluation of cleft similarity}

To further illustrate the evaluation of cleft similarity, two patients with different clefts were evaluated with the proposed function. As it was mentioned, clefts may be unilateral or bilateral. The latter cannot be considered as the simple union of two unilateral clefts. For 
evaluating a bilateral one, it is necessary to do the addition of the evaluation of each unilateral cleft and then multiply this result by a 1.5 factor. This factor represents the bilateral condition according to the surgeons. Three patients with different clefts are described by the lip and nose variables and criteria defined (Table 4 and 5), as follows:

Patient 1 (Figure 4): This patient has a left complete cleft of the primary palate with $3 \mathrm{~mm}$ of separation between the segments. The secondary palate is normal. Cleft evaluation is given by the function defined for complete cleft without contact of segments showed in Table 1 as followed: Evaluation $_{\text {cleft }}=12[1+(\mathrm{M} \times 10-1)]=12[1+(3 \times 10-1)]=12(1.3)=15.6 \sim 16$.

Patient 2 (Figure 5): This patient has a bilateral cleft of the primary palate. The left side is incomplete (one-third), while the right side is complete with $3 \mathrm{~mm}$ of segment separation. In this case, the cleft evaluation must be done attending each side. Considering Table 1, the score for the left side is 3 . The right side is the same as above: 16 . Total evaluation for this cleft is given by: Evaluation $_{\text {cleft }}=[3$ (left primary) +16 (right primary) $] 1.5$ (bilateral) $=28.5 \sim 29$.

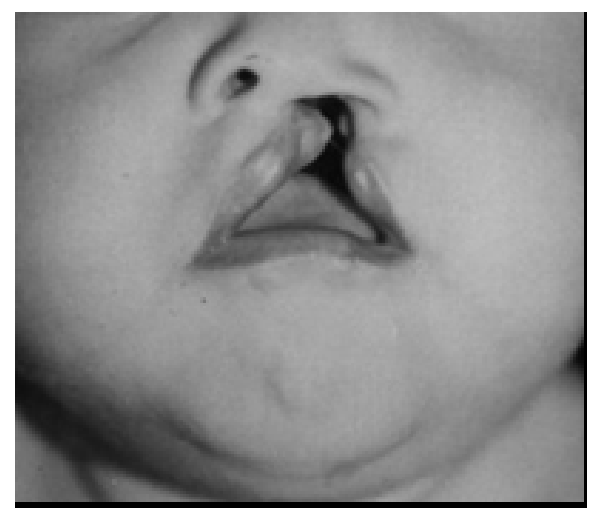

Fig. 4. Left complete cleft of the primary palate with $3 \mathrm{~mm}$ of separation between the segments. Secondary palate is normal.

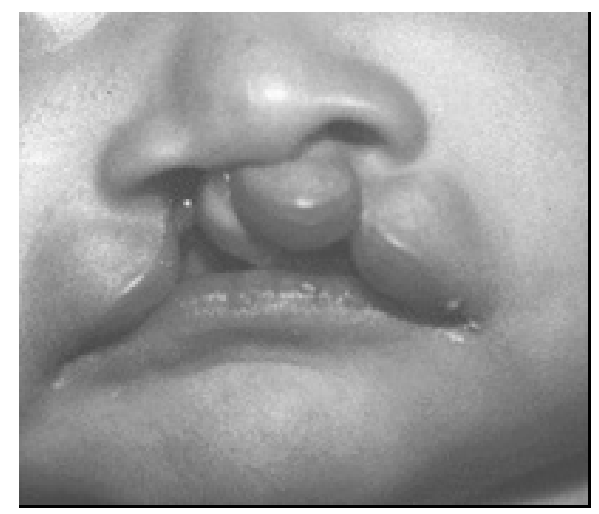

Fig. 5. Bilateral cleft of the primary palate. Left side is incomplete 1/3. Right side is complete with $3 \mathrm{~mm}$ of segment separation. 
Patient 3 (Figure 6): This patient has a grade III bilateral cleft of the secondary palate and a normal primary palate. The evaluation of the primary palate is 0 . The evaluation of the secondary palate is obtained directly from Table 1 . Therefore, Evaluation cleft $=55$.

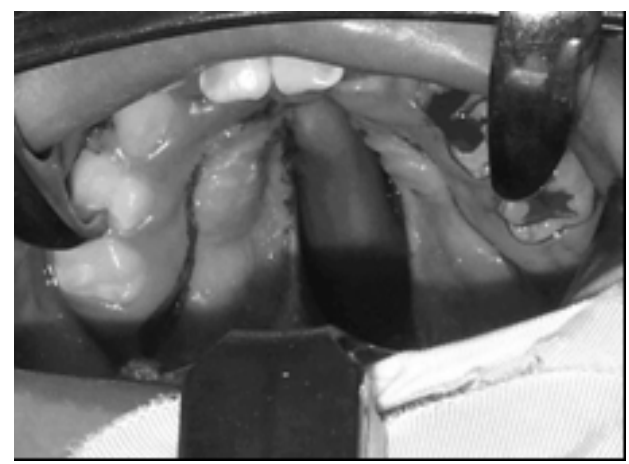

Fig. 6. Bilateral cleft of the secondary palate grade III with a normal primary palate.

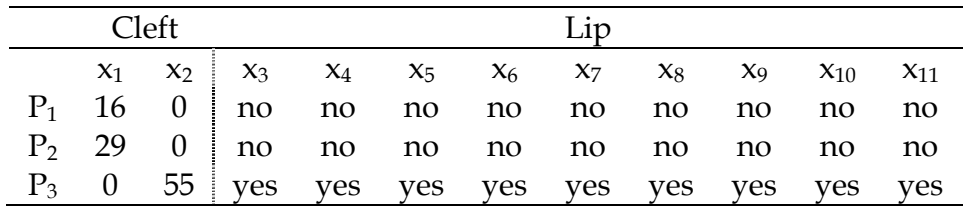

Table 4. Complete description of the cleft/lip of the three patients.

\begin{tabular}{|c|c|c|c|c|c|c|c|c|c|}
\hline \multicolumn{3}{|c|}{ Cleft } & \multicolumn{7}{|c|}{ Nose } \\
\hline & $x_{1}$ & $x_{2}$ & $x_{12}$ & $x_{13}$ & $\mathrm{x}_{14}$ & $x_{15}$ & $x_{16}$ & $\mathrm{x}_{17}$ & $\mathrm{x}_{18}$ \\
\hline$P_{1}$ & 16 & 0 & no & no & no & no & barely & barely & barely \\
\hline$P_{2}$ & 29 & 0 & no & barely & no & barely & no & absent & greater \\
\hline$P_{3}$ & 0 & 55 & yes & yes & yes & yes & yes & normal & normal \\
\hline
\end{tabular}

Table 5. Complete description of the cleft/nose of the three patients.

Cleft similarity. Using equation (1) and considering the cleft description of patients $\mathrm{P}_{1}$ and $\mathrm{P}_{2}$ (Table 4), the similarity result is given by:

$$
\begin{aligned}
& \beta_{\text {cleft }}\left(I\left(P_{1}\right), I\left(P_{2}\right)\right)=1-\left[0.65\left(\left|\frac{x-y}{100}\right|\right)+0.35\left(\left|\frac{x-y}{55}\right|\right)\right]=1-\left[0.65\left(\left|\frac{16-29}{100}\right|\right)+0.35\left(\left|\frac{0-0}{55}\right|\right)\right] \\
& \beta_{\text {cleft }}\left(I\left(P_{1}\right), I\left(P_{2}\right)\right)=1-[0.65(0.13)]=1-0.085 \simeq 0.92
\end{aligned}
$$

Lip similarity. Using equation (2) and considering lip description of patients $\mathrm{P}_{1}$ and $\mathrm{P}_{2}$ (Table $4)$, the similarity result is given by:

$$
\beta_{\text {lip }}\left(I\left(P_{1}\right), I\left(P_{2}\right)\right)=1-\left[\begin{array}{c}
0.16(0)+0.15(0)+0.14(0)+0.15(0)+0.08(0) \\
+0.12(0)+0.10(0)+0.05(0)+0.05(0)
\end{array}\right]=1
$$

Nose similarity. Using equation (3) and taking into account nose description of patients $P_{1}$ and $\mathrm{P}_{2}$ (Table 5), the similarity result is given by: 


$$
\beta_{\text {nose }}\left(I\left(P_{1}\right), I\left(P_{2}\right)\right)=1-\left[\begin{array}{c}
0.17(0)+0.25(0.33)+0.10(0)+0.10(0.33)+0.11(0.33) \\
+0.15(0.33)+0.12(0)
\end{array}\right] \simeq 0.84
$$

Using equation (4) the total similarity between patients $\mathrm{P}_{1}$ and $\mathrm{P}_{2}$ is given by:

$$
\beta_{T C}\left(I\left(P_{1}\right), I\left(P_{2}\right)\right)=[0.60(0.92)+0.20(1)+0.20(0.84)] \simeq 0.93
$$

The total similarity between patients $\left(\mathrm{P}_{1}, \mathrm{P}_{3}\right)$ y $\left(\mathrm{P}_{2}, \mathrm{P}_{3}\right)$ was calculated in the same form as in the case showed above. These total similarities are given by:

$$
\begin{aligned}
& \beta_{T C}\left(I\left(P_{1}\right), I\left(P_{3}\right)\right)=[0.60(0.55)+0.20(0)+0.20(0.15)] \simeq 0.36 \\
& \beta_{T C}\left(I\left(P_{2}\right), I\left(P_{2}\right)\right)=[0.60(0.47)+0.20(0)+0.20(0.15)] \simeq 0.31
\end{aligned}
$$

The similarity found in the case of patients 1 and 2 clearly reflect that there is a great likelihood between them. This is clear because both present a cleft in the primary palate (palate, lips and nose). Notice in the case of the lips, that the likelihood resulted 1 because of the fact that it is a structure affected by the cleft, the description of the lips of the patients is identical. In the case of the nose even though, evidently, the deformation is larger in patient 2 because we are dealing with a bilateral cleft, the nose in both cases is deformed, hence, the likelihood between noses turned out to be high $(>0.8)$.

In the case of the cleft of patient 3 , since it occurs on the secondary palate, it means that the lip and the nose have a normal condition and, thus, the likelihood in this structures with patients 1 and 2 is null $(\beta=0)$ and, therefore, the full likelihood between patient 3 and the other two is low. As we mention, these three patients were evaluated in order to illustrate the proposed similarity function.

\subsection{Orthodontics mathematical model}

\subsubsection{Variables and comparison criteria}

A set of 12 variables were defined for bilateral clefts description and just a subset of 9 of them were considered for the unilateral fissures. These 12 variables with their respective domains, were defined taking into account the condition of the maxilla, premaxilla, mandible and the patient's bite (Table 6). Dental malocclusion can be produced through maxillary retrusion or mandibular protusion. The segments (bones that form the premaxilla) are evaluated in terms of their contact. Maxillary collapse can be present unilaterally (left or right) or anteroposterior. Dental occlusion and overbite are related to the bite on different planes. The condition of the premaxilla is also evaluated on three different planes (see variables 10-12): that is, whether it is protrusive or retrusive, deviated, or if there is some discrepancy in the vertical plane (Ortiz-Posadas et al, 2004).

Likewise, the domain of each of the variables was defined: malocclusion takes only the two logical values "yes" or "no". Segment contact is evaluated in terms of the millimeters of separation in the interval $[0,30] \mathrm{mm}$. The domain of the maxillary collapse variable is 4valent (no, barely, moderate, severe). The dental occlusion variable can take the three Angle classification values ( $\mathrm{C} 1, \mathrm{C} 2$ and $\mathrm{C} 3)$. In the case of overbite, its domain is defined in the interval $[20,6] \mathrm{mm}$. The premaxillary variable has three domains, depending on the plane that is being evaluated: bivalent (central or deviated), trivalent (normal, protrusive and 
retrusive) and the interval $[10,10] \mathrm{mm}$. It should be mentioned that not all the variables are evaluated in all cleft palates. This will depend on the characteristics of the fissure in terms of whether it is unilateral or bilateral, as will be seen later.

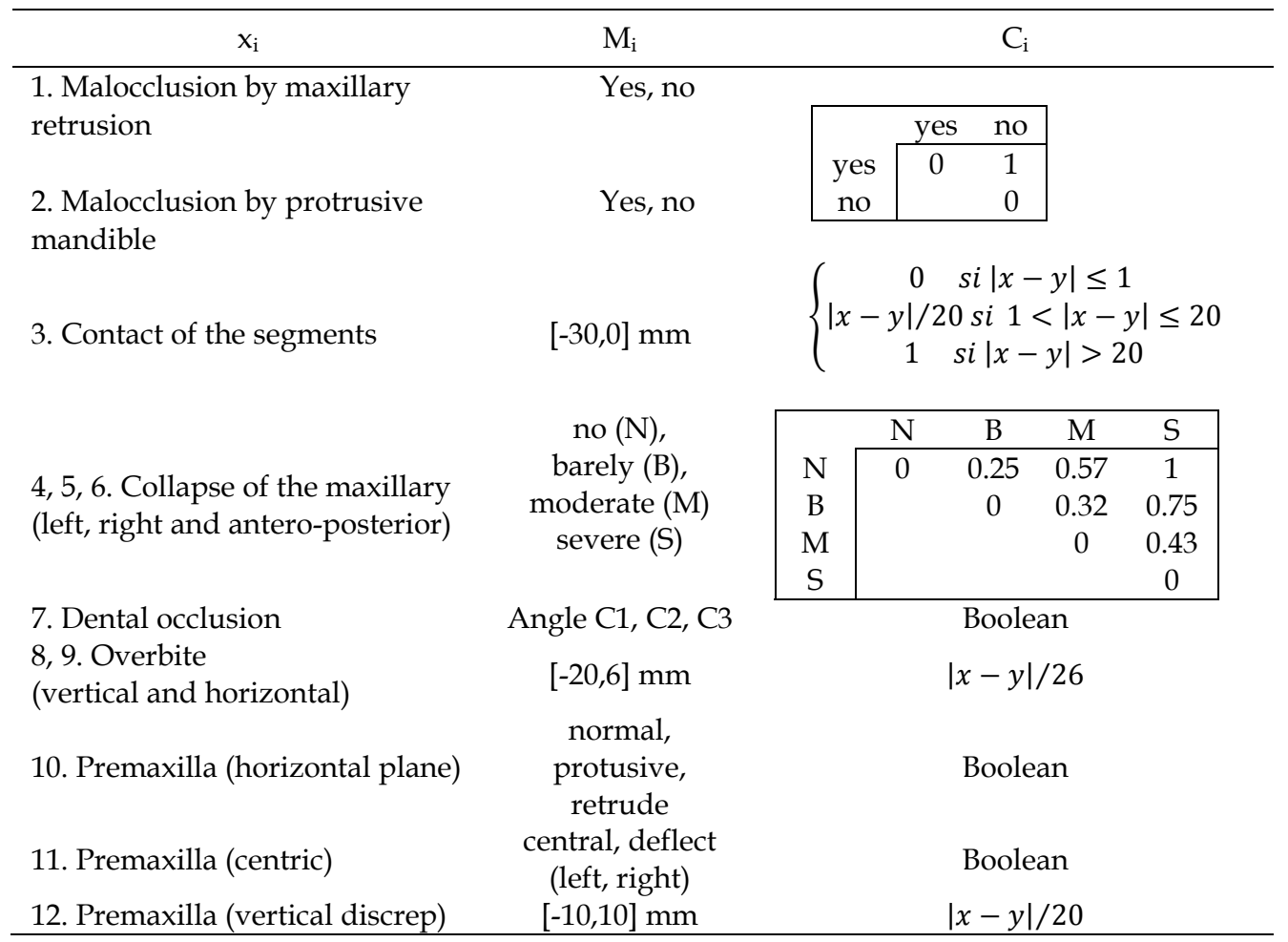

Table 6. Variables, domains and comparison criteria for orthodontics

Regarding the comparison criteria defined for each variable, it can be observed that the segment contact, overbite and vertical discrepancy premaxilla variables have the relative difference between two values as their comparison criterion. In particular, for segment contact, if the absolute difference between the values being compared is less or equal than 1 , then the values are similar (the result of their comparison is 0 ). On the opposite, if the difference is greater or equal than $20 \mathrm{~mm}$, then the values are different because the result of comparison is the maximum. As the malocclusion variable is bivalent, it has a Boolean comparison criterion and, in the case of the dental occlusion variable, it can take three independent and non-ordered values, that is, different from one another; that is why the comparison criterion is also Boolean. However, in the case of the maxillary collapse variable, a fuzzy criterion is defined because it does not have a homogeneous scale, or rather; the difference between two consecutive values is not equivalent, according to the criterion of the orthodontist. In the case of overbite, a fuzzy criterion was defined as a result of the absolute difference of values over 26, which is the maximum difference that can arise according to the defined interval. With respect to the premaxilla, a Boolean comparison criterion was defined for its bivalent and trivalent domains. A fuzzy criterion was defined for the interval as a 
result of the absolute difference of values over 20, which is the maximum difference possible. It must be stressed that the criteria for each of the variables were defined together with the orthodontist, taking into account his/her clinical knowledge and experience.

It should be mentioned that all the variables considered do not have the same importance for the orthodontist. Hence, informational importance (relevance) was assigned to each of them with the support of the clinical model, the specialist experience and the type of fissure. The relevance is shown in Table 7.

\begin{tabular}{lcc}
\hline \multirow{2}{*}{ Variable } & \multicolumn{2}{c}{ Relevance $(\rho)$} \\
\cline { 2 - 3 } & Unilateral cleft & Bilateral cleft \\
\hline 1. Malocclusion by maxillary retrusion & 0.10 & 0.04 \\
2. Malocclusion by protrusive mandible & 0.05 & 0.04 \\
3. Contact of the segments & 0.16 & 0.05 \\
4, 5. Collapse of the maxillary (left, right) & 0.20 & 0.08 \\
6. Collapse of the maxillary (antero-posterior) & 0.20 & 0.09 \\
7. Dental occlusion & 0.17 & 0.07 \\
8. Overbite (vertical) & 0.12 & 0.04 \\
9. Overbite (horizontal) & 0.10 & 0.04 \\
10. Premaxilla (horizontal plane) & Cannot be evaluated & 0.10 \\
11. Premaxilla (centric) & Cannot be evaluated & 0.10 \\
12. Premaxilla (vertical discrepancy & Cannot be evaluated & 0.10 \\
\hline
\end{tabular}

Table 7. Relevance of each variable for orthodontics

\subsubsection{Similarity function}

The orthodontics similarity function was defined taking into account if there is a unilateral or bilateral cleft. So we defined two functions:

Definition 6 . Let $\beta_{U_{\text {orthodontics }}}$ be the similarity function for unilateral clefts defined by:

$$
\beta_{\text {Uorthodontics }}\left(I\left(P_{i}\right), I\left(P_{j}\right)\right)=1-\frac{\sum_{t=1}^{9} \rho_{t} c_{t}\left(x_{t}\left(P_{i}\right), x_{t}\left(P_{j}\right)\right)}{1.1}
$$

Definition 7. Let $\beta_{B_{\text {orthodontics }}}$ be the similarity function for bilateral clefts defined by:

$$
\beta_{\text {Borthodontics }}\left(I\left(P_{i}\right), I\left(P_{j}\right)\right)=1-\frac{\sum_{t=1}^{12} \rho_{t} C_{t}\left(x_{t}\left(P_{i}\right), x_{t}\left(P_{j}\right)\right)}{0.75}
$$

\subsubsection{Evaluation of orthodontics similarity}

To further illustrate the evaluation of the orthodontic similarity, four patients with different clefts were evaluated with the proposed function. The descriptions of the patients are shown in Table 8. The number of each column represents the variable corresponding to Table 5. 
Each row is the description of the patient in terms of the domain of each variable. It can be observed that $P_{1}$ and $P_{2}$ have a similar cleft. For this reason, the expected similarity would be almost the maximum. Patients $\mathrm{P}_{3}$ and $\mathrm{P}_{4}$ have very different descriptions, so the expected similarity would be low.

Using Definition 6 and considering patients description, the similarity results are given by:

$$
\begin{gathered}
\beta_{\text {Uorthodontics }}\left(I\left(P_{1}\right), I\left(P_{2}\right)\right)=1-\frac{\left(\begin{array}{c}
0.1(0)+0.05(0)+0.16(0)+0.2(0)+ \\
+0.2(0)+0.17(0)+0.12(0)+0.1(0.12)
\end{array}\right)}{1.1}=0.98 \\
\beta_{\text {Borthodontics }}\left(I\left(P_{3}\right), I\left(P_{4}\right)\right)=1-\frac{\left(\begin{array}{c}
0.04(1)+0.04(1)+0.05(0.1)+0.08(1)+ \\
+0.08(1)+0.09(1)++0.07(0.5)+0.04(0.15)+ \\
+0.04(0.19)+0.1(1)+0.1(1)+0.1(0)
\end{array}\right)}{0.75}=0.16
\end{gathered}
$$

It is known that the maximum similarity that can be obtained is equal to 1 , and this occurred when comparing two equal fissures (with the same values of the characteristics). In relation to the similarity obtained for patients $P_{1}$ and $P_{2}$, it can be observed that the similarity was very high, as mentioned earlier. In relation to the similarity for patients $\mathrm{P}_{3}$ and $\mathrm{P}_{4}$, it can be observed that the similarity was low. Observe that in both cases, the similarity result was close to the expected one above.

\begin{tabular}{ccccccccccccc}
\hline \multirow{2}{*}{ Patient } & \multicolumn{10}{c}{ Variable } \\
\cline { 2 - 12 } & 1 & 2 & 3 & 4 & 5 & 6 & 7 & 8 & 9 & 10 & 11 & 12 \\
\hline$P_{1}$ & yes & no & 0 & barely & no & barely & C3 & -1 & -2 & \multicolumn{2}{c}{ cannot be evaluated } \\
$P_{2}$ & yes & no & 0 & barely & no & barely & C3 & 2 & -2 & cannot be evaluated \\
$P_{3}$ & no & no & 2 & no & no & no & C2 & 2 & 3 & protu & deflected & 0 \\
$P_{4}$ & yes & no & 2 & barely & barely & barely & C3 & 0 & 0 & norm & centric & 0 \\
\hline
\end{tabular}

Table 8. Four patients described in terms of the orthodontics variables

\subsection{Speech mathematical model}

To evaluate the speech of these patients, the experts consider two aspects: compensatory articulation and dyslalia. Compensatory articulation is measured through phonemes $b, f, p$, $\mathrm{t}, \mathrm{k}, \mathrm{ch}, \mathrm{s}$. These are evaluated in specific language (language articulated by repetition) and in spontaneous language (the one spoken naturally). Each one of these phonemes is evaluated as constant, non-constant or omitted. What is evaluated is the number of phonemes with omission or inconstancy in each type of language. We also consider different perturbations in other phonemes, stemming from the variable dyslalia (impairment of the power of speaking, due to a defect of the organs of speech). Eventually, one may consider the result of a nasopharyngeal endoscopy, which measures the velopharyngeal deficiency in a scale of light, moderate and severe. Finally, the variable dysarthria is an exclusion criterion for the patient to receive language therapy, since it represents a neurological problem and no rehabilitation is possible. 


\subsubsection{Variables and comparison criteria}

We defined 5 variables: 1) Omissions in the specific language, 2) Omissions in the spontaneous language, 3) Inconstancies in the specific language, 4) Inconstancies in spontaneous language, and 5) Dyslalia (Ortiz-Posadas MR and Lazo-Cortés MS, 2002). The domain of the first four variables is the set $\{0,1,2,3,4,5,6,7\}$ related with the seven evaluated phonemes. The variable dyslalia only takes two possible values (yes/no). We also defined the comparison criteria for each variable. In this case we must calculate the difference in the omissions and inconstancies present in each of the languages. Therefore, the comparison criterion for the phonemes was defined as the absolute difference divided by 7 (the number of phonemes being evaluated). In the case of the variable dyslalia, the criterion is Boolean. (For Boolean criterion form see Table 6, variables $x_{1}$ and $x_{2}$ ).

\begin{tabular}{|c|c|c|c|c|}
\hline Language & $x_{i}$ & $\rho_{\mathrm{i}}$ & $\mathrm{M}_{\mathrm{i}}$ & $\mathrm{C}_{\mathrm{i}}$ \\
\hline Specific & $\begin{array}{l}\text { Omission } \\
\text { Inconstancy }\end{array}$ & $\begin{array}{l}0.28 \\
0.14\end{array}$ & $\{0,1,2,3,4,5,6,7\}$ & $|x-y| / 7$ \\
\hline Spontaneous & $\begin{array}{l}\text { Omission } \\
\text { Inconstancy }\end{array}$ & $\begin{array}{l}0.18 \\
0.10\end{array}$ & $\{0,1,2,3,4,5,6,7\}$ & $|x-y| / 7$ \\
\hline & Dislalia & 0.30 & yes, no & Boolean \\
\hline
\end{tabular}

Table 9. Speech variables, domain and comparison criteria

\subsubsection{Similarity function}

This function allows the comparison between the full descriptions of the languages of two patients. To define the similarity function in this case, it was necessary to change the code in the patient's description. It is important to mention that all phonemes have the same relative importance, so it is irrelevant in which particular phoneme the problem arises. Rather, we detect the total number of omissions and/or inconstancies which the patient displays in every language. We have to stress that if some phoneme is omitted, it is always the case that an inconstancy is present in the same phoneme, but not the inverse. Likewise, if the omissions and/or inconstancies arise in a specific language, they are also present in the spontaneous language. On the other hand, if we start from the domain of these variables $\{0$, $1, \ldots, 7\}$, the largest number of omissions and inconstancies the patient may display in every language is 7 . Considering the elements just mentioned, a change in coding for the patient's description was determined as follows:

- $\quad$ Once each phoneme is evaluated [constant (c), inconstant (i), omission (o)] the amount of phonemes where there were inconstancies is counted in both languages.

- A similar count is recorded for those phonemes where omissions were detected.

- If patient presents a determined number of omissions (which implies a similar number of inconstancies) and a number of inconstancies (in different phonemes from those in which omission was found) to such inconstancies is added the number of omissions. This sum may not be larger than 7 .

Example. Let us assume that a patient displays omissions in four phonemes $(b, f, p, t)$ and an inconstancy in phoneme $\mathrm{k}$, evaluated in spontaneous language. $\mathrm{He} / \mathrm{she}$ displays a total of 
four omissions and five inconstancies. In specific language he/she displays four omissions and one inconstancy. The patient does not display dyslalia. Changing the codes relative to the initial description, the final description is as shown in Table 10.

\begin{tabular}{lccccc}
\hline \multirow{2}{*}{ Description } & \multicolumn{6}{c}{ Specific L } & \multicolumn{4}{c}{ Spontaneous L } \\
& $\mathrm{o}$ & $\mathrm{i}$ & $\mathrm{o}$ & $\mathrm{i}$ & dyslalia \\
\hline Initial & $(4$ & 1 & 4 & 1 & $0)$ \\
Code change & $(4$ & $4+1$ & 4 & $4+1$ & $0)$ \\
\hline Final & $\mathbf{( 4}$ & $\mathbf{5}$ & $\mathbf{4}$ & $\mathbf{5}$ & $\mathbf{0})$ \\
\hline
\end{tabular}

Table 10. Code change of a patient speech description.

Let us now consider the language evaluation of the worst patient (that which displays omissions in all phonemes). For the purpose of code change, we assume that she/he displays inconstancy in all phonemes. In this case, patient is assumed to display dyslalia. The description is shown in Table 11 and final descriptions are shown in Table 12.

\begin{tabular}{lccccc}
\hline & \multicolumn{6}{l}{ Specific L } & \multicolumn{3}{l}{ Spontaneous L } \\
& $\mathrm{o}$ & $\mathrm{i}$ & $\mathrm{o}$ & $\mathrm{i}$ & dyslalia \\
\hline Initial & $(7$ & 0 & 7 & 0 & $1)$ \\
Code change & $(7$ & $7+0$ & 7 & $7+0$ & $1)$ \\
\hline Final & $\mathbf{( 7}$ & $\mathbf{7}$ & $\mathbf{7}$ & $\mathbf{7}$ & $\mathbf{1})$ \\
\hline
\end{tabular}

Table 11. Speech description of worst patient

\begin{tabular}{cccccc}
\hline \multicolumn{5}{c}{ Specific L } & \multicolumn{3}{c}{ Spontaneous L } \\
& $\mathrm{o}$ & $\mathrm{i}$ & $\mathrm{o}$ & $\mathrm{i}$ & dyslalia \\
\hline $\mathrm{P}_{1}:$ & $(4$ & 5 & 4 & 5 & $0)$ \\
$\mathrm{P}_{2}:$ & $(7$ & 7 & 7 & 7 & $1)$ \\
\hline
\end{tabular}

Tabla 12. Final speech description of two patients

The speech similarity function was defined taking into account the five variables as follows:

Definition 8 . Let $\beta_{\text {speech }}$ be the similarity function for speech defined by:

$$
\beta_{\text {speech }}\left(I\left(P_{1}\right), I\left(P_{2}\right)\right)=1-\sum_{k=1}^{5} \rho_{k} C_{k}\left(x_{k}\left(P_{1}\right), x_{k}\left(P_{2}\right)\right)
$$

\subsubsection{Evaluation of speech similarity}

Considering both descriptions in Table 11 and using equation (7), similarity between these patients is:

$$
\beta_{\text {speech }}\left(I\left(P_{1}\right), I\left(P_{2}\right)\right)=1-\left\{(0.28) \frac{3}{7}+(0.18) \frac{3}{7}+(0.14) \frac{2}{7}+(0.10) \frac{2}{7}+(0.30) 1\right\} \simeq 0.44
$$

This result clearly reflects that there is a low likelihood between these patients, because language in $\mathrm{P}_{1}$ is better than in $\mathrm{P}_{2}$ so, their languages are too different. 


\subsection{Psychology mathematical model}

\subsubsection{Variables and comparison criteria}

In psychology case, six variables were defined taking into account issues related to patient's home environment: such as grief, a variable related to the shock it has on parents about having a child with a cleft palate; family integration, related to the primary core members of the family (father, mother and children); family dysfunction, with which assesses whether they are meeting the roles of each member of the family; image of the parents, who refers to the perception of parents about their child. Other variables are social integration and selfimage, which is directly related to the patient's integration in their social environment (school, family and peer groups) and the perception of himself, respectively.

Likewise, the domain of each variable was defined. Five of the variables take only two logical values: grief (current or sealed), integration family (yes or no), family dysfunction (yes or no), image of the parents (positive or negative) and self-image (positive or negative). The domain of social integration variable is 5-valent (excellent, very good, good, regular and bad). It is noteworthy that some of these variables are evaluated in the initial condition of the patient, i.e., before any treatment. Others may be assessed at any time before or after receiving some treatment and some others can only be assessed after treatment.

Regarding the comparison criteria defined for each variable, as grief, family integration, family dysfunction, image of the parents and self-image variables are bivalent, they have a Boolean comparison criterion (see Table 6). In the case of social integration variable its comparison criterion is of fuzzy type, with a homogeneous scale, or rather, the difference between two consecutive values is equivalent.

It should be mentioned that, as in surgery, orthodontics and language therapy specialties, all the variables considered in psychology do not have the same importance for the psychologist. Hence, informational importance (relevance) was assigned to each of them with the support of the specialist experience. The variables, their domain and the comparison criterion are shown in Table 13.

\begin{tabular}{|c|c|c|c|c|c|c|c|c|}
\hline$x_{i}$ & $\rho_{\mathrm{i}}$ & $\mathrm{M}_{\mathrm{i}}$ & \multicolumn{6}{|c|}{$\mathrm{C}_{\mathrm{i}}$} \\
\hline 1. Grief & 0.08 & Current or sealed & \multicolumn{6}{|c|}{ Boolean } \\
\hline 2. Family integration & 0.10 & Yes, no & \multicolumn{6}{|c|}{ Boolean } \\
\hline 3. Family dysfunction & 0.11 & Yes, no & \multicolumn{6}{|c|}{ Boolean } \\
\hline 4. Image of the parents & 0.15 & Positive, negative & \multicolumn{6}{|c|}{ Boolean } \\
\hline 5. Self-image & 0.20 & Positive, negative & \multicolumn{6}{|c|}{ Boolean } \\
\hline \multirow{6}{*}{ 6. Social integration } & \multirow{6}{*}{0.50} & \multirow{6}{*}{$\begin{array}{c}\text { Excellent(E), } \\
\text { Very Good(VG) } \\
\text { Good(G) } \\
\text { Regular(R) } \\
\text { Bad(B) }\end{array}$} & & $\mathrm{E}$ & VG & G & $\mathrm{R}$ & B \\
\hline & & & $\mathrm{E}$ & 0 & 0.2 & 0.4 & 0.8 & 1 \\
\hline & & & VG & & 0 & 0.2 & 0.6 & 0.8 \\
\hline & & & G & & & 0 & 0.4 & 0.6 \\
\hline & & & $\mathrm{R}$ & & & & 0 & 0.2 \\
\hline & & & B & & & & & 0 \\
\hline
\end{tabular}

Table 13. Variables, domains, relevance and comparison criteria for psychology 


\subsubsection{Similarity function}

Definition 9. Let $\beta_{P s y}$ be the similarity function for psychology defined by:

$$
\beta_{P s y}=\left(I\left(P_{j}\right), I\left(P_{k}\right)\right)=1-\frac{\sum_{i=1}^{6} \rho_{i} C_{i}\left(x_{i}\left(P_{j}\right), x_{i}\left(P_{k}\right)\right)}{1.14}
$$

\subsubsection{Evaluation of psychological similarity}

To illustrate the evaluation of the similarity function modeled for the psychology specialty, we take the psychological description of the three patients shown in Table 14 and use the equation (8). The similarity result is given by:

$$
\begin{gathered}
\beta_{P_{s y}}\left(I\left(P_{1}\right), I\left(P_{2}\right)\right)=1-\frac{(0.08(0)+0.1(1)+0.11(1)+0.15(0)+0.2(0)+0.5(0.4))}{1.14}=0.64 \\
\beta_{P s y}\left(I\left(P_{1}\right), I\left(P_{3}\right)\right)=1-\frac{(0.08(01)+0.1(1)+0.11(1)+0.15(0)+0.2(1)+0.5(1.0 .4))}{1.14}=0.13
\end{gathered}
$$

It is clear that the similarity between the first two patients is greater than between $P_{1}$ and $P_{3}$, since as mentioned the psychological condition of the latter is the worst and when compared with $\mathrm{P}_{1}$ excellent condition, similarity is obviously minimal. In this sense, the similarity that exists between patients who are located in the same class should be high while the similarity between patients, who are located in very different kinds, should be therefore very low as illustrated.

\begin{tabular}{ccccccc}
\hline Patient & \multicolumn{5}{c}{ Variable } \\
\cline { 2 - 7 } & 1 & 2 & 3 & 4 & 5 & 6 \\
$P_{1}$ & Current & Yes & No & Positive & Positive & Excellent \\
$P_{2}$ & Current & No & Yes & Positive & Positive & God \\
$P_{3}$ & Sealed & No & Yes & Positive & Negative & Bad \\
\hline
\end{tabular}

Table 14. Three patients described in terms of the psychologist variables

\section{Mathematical model application}

Surgical complexity for cleft reconstruction will depend on fissure complexity involving lip, nose and/or palate. Cleft correction translates into a very slow and complex process; because it is related to the growth and development of the patient and it requires least one surgical procedure. The importance of prognosis of the patient's rehabilitation, and subsequent evaluation of the surgical result, is the physician's self-feedback during all the rehabilitation process. The physician will learn if the work patient rehabilitation is adequate, or if it can be improved. This has a direct consequence in the future quality of patient's life.

\subsection{Rehabilitation prognosis}

The rehabilitation prognosis of patients with cleft palate is carried out by considering the original condition of the patient and taking into account the degree of rehabilitation attained by previous patients cared for in the hospital. Prognosis is conceived as a result from a 
supervised classification problem, and it uses a training matrix made from: cleft descriptions from patients already finished their rehabilitation, and a classification algorithm (voting algorithm). The training matrix is divided into three post-surgical classes (excellent, very good and good). These classes were determined from the evaluation of each patient's surgical result. These classes provide the expert criterion for evaluation (classification) of the degree of rehabilitation accomplished by the patient. Each patient is prognosticated (classified) by comparing his/her initial description with the initial descriptions of patients already included in the training matrix. The most relevant patients for the prognosis will be those who are most similar to the patient one is about to classify. This means that the prognosis corresponds to the class that includes the patients most similar to the subject that will be classified. In this way, a patient will be predicted as very good if his/her description is most similar to patients from the training matrix that was included in the very good class. In the same way, evaluation of rehabilitation advance is made using the patient's post-surgical description, and applying the expert criteria which defined post-surgical classes mentioned above. The classification will correspond to the patient's rehabilitation advance.

\subsection{Data acquisition}

The methodology was tested with a sample of 95 patients cared for by the cleft palate team at the reconstructive surgery service of the Pediatric Hospital of Tacubaya, which belongs to the Health Institute of the Federal District in Mexico City. For acquiring patient data we designed a patient's registration form Figs. 7 and 8 given to the surgeons in order to fill it out with the cleft description by the variables defined for.

\subsection{Results}

With the 95 patient's data two matrices were made: learning and control. The learning matrix consisted of 32 patients, distributed in the following way: 10 in the excellent (E) class, 14 in the very good (VG) c1ass, and 8 in the good (G) class. Similarly, the control matrix consisted of 63 patients: 19 in E, 29 in VG, and 15 in G. The classification was made with patients from the control matrix and the results obtained are shown in Table 15. The diagonal in the table highlights classification successes. Out of 19 patients in the excellent class, the algorithm correctly classified 17 and the remaining two patients were placed in the very good c1ass. Of 29 patients located in the VG c1ass, 26 were properly classified and three were classified as good. For patients in the good class, 14 stayed in this same class and only one was classified as very good. In general, 57 patients were correctly classified.

\begin{tabular}{l|c|cccr}
\hline Class (algorithm) & \multicolumn{2}{c}{ E } & VG & G & Total \\
Class (inference) & \multicolumn{1}{c}{ (17 } & 2 & 0 & 19 \\
\cline { 1 - 3 } Excellent (E) & 0 & $\mathbf{2 6}$ & 3 & 29 \\
Very good (VG) & 0 & 1 & $\mathbf{1 4}$ & 15 \\
Good (G) & 17 & 29 & 17 & 63 \\
\hline Total & & &
\end{tabular}

Table 15. Classification results for 63 cleft palate patients 
However, 63 patients were evaluated with this similarity function for classifying the surgical complexity of their clefts. The efficiency of the similarity function was $90 \%$, according to the complexity defined by the surgeons' team. This means that the similarity function, as well as the cleft description with the 18 variables defined, well modeled the complexity of the unilateral and bilateral clefts according to the surgeons expertise.

\begin{tabular}{|l|l|l|}
\hline Date: & Initial assessment: & Folow-up : \\
\hline Patient's name: & Birth date: \\
\hline Phycisian's name: & Exp No. \\
\hline
\end{tabular}

\begin{tabular}{|c|c|c|c|c|c|c|}
\hline \multicolumn{7}{|c|}{ Primary palate } \\
\hline Variables & \multicolumn{3}{|c|}{ Left } & \multicolumn{3}{|c|}{ Right } \\
\hline Incomplete & microform & $1 / 3$ & $2 / 3$ & microform & $1 / 3$ & $2 / 3$ \\
\hline Complete & \multicolumn{3}{|c|}{$\mathrm{mm}$} & \multicolumn{3}{|c|}{$\mathrm{mm}$} \\
\hline
\end{tabular}

\begin{tabular}{|c|c|c|c|c|c|c|}
\hline \multicolumn{7}{|c|}{ Secondary palate } \\
\hline Variables & \multicolumn{3}{|c|}{ Left } & \multicolumn{3}{|c|}{ Right } \\
\hline Incomplete & \multicolumn{2}{|c|}{$1 / 3$} & $2 / 3$ & \multicolumn{2}{|c|}{$1 / 3$} & $2 / 3$ \\
\hline Complete & GI & GII & GIII & GI & GII & GIII \\
\hline Submucous & \multicolumn{3}{|c|}{ Without bifid uvula } & \multicolumn{3}{|c|}{ With bifid uvula } \\
\hline
\end{tabular}

\begin{tabular}{|c|c|c|c|c|}
\hline \multicolumn{5}{|c|}{ Lip } \\
\hline Variables & Yes & Almost & Barely & No \\
\hline Symetry of lip height & & & & \\
\hline Normal lip height & & & & \\
\hline Muscular integrity & & & & \\
\hline Skin integrity & & & & \\
\hline Mucous membrane integrity & & & & \\
\hline Symmetry of lip thickness & & & & \\
\hline Normal sulcus depth & & & & \\
\hline Symmetry of philtral ridges & & & & \\
\hline Presence of cupid arch & & & & \\
\hline
\end{tabular}

\begin{tabular}{|c|c|c|c|c|}
\hline \multicolumn{5}{|c|}{ Nose } \\
\hline Variables & Yes & Almost & Barely & No \\
\hline Symmetry of nasal floor & & & & \\
\hline Symmetry of nostril archs & & & & \\
\hline Symmetry of notrils (vert & & & & \\
\hline Symmetry of nostrils (ant & & & & \\
\hline Nasal septum deviation & & & & \\
\hline Length of columella & Normal & Almost & Barely & Abscent \\
\hline Width of nasal base & Greater & Normal & minor & \\
\hline
\end{tabular}

Fig. 7. Patient's registration form 


\begin{tabular}{|c|c|c|c|}
\hline \multicolumn{4}{|c|}{ Orthodontics } \\
\hline $\begin{array}{l}\text { Malocclusion by maxillary } \\
\text { retrusion }\end{array}$ & \multicolumn{2}{|c|}{ Yes } & No \\
\hline $\begin{array}{l}\text { Malocclusion by protrusive } \\
\text { mandible }\end{array}$ & \multicolumn{2}{|c|}{ Yes } & No \\
\hline Contact of the segments & \multicolumn{2}{|c|}{$\mathrm{mm}$} & \\
\hline Collapse of the maxillary & Left & Right & Antero-post \\
\hline Dental occlusion & $\mathrm{C} 1$ & C2 & $\mathrm{C} 3$ \\
\hline Overbite & \multicolumn{2}{|c|}{ mm vertical } & horizontal \\
\hline Premaxilla (horizontal plane) & Normal & Protusive & Retrude \\
\hline Premaxilla (centric) & Central & Left deflect & Right deflect \\
\hline Premaxilla (vertical discrepancy) & $\mathrm{mm}$ & \multirow[b]{2}{*}{ Mixed } & \\
\hline Dentadura type & Decidua & & Permanent \\
\hline
\end{tabular}

\begin{tabular}{|c|c|c|c|c|c|c|c|c|c|c|c|c|c|c|}
\hline \multicolumn{15}{|c|}{ Speech and language } \\
\hline Phoneme & \multicolumn{2}{|c|}{$\mathrm{B}$} & \multicolumn{2}{|c|}{$\mathrm{F}$} & \multicolumn{2}{|c|}{$\mathrm{P}$} & \multicolumn{2}{|c|}{$\mathrm{T}$} & \multicolumn{2}{|c|}{$\mathrm{K}$} & \multicolumn{2}{|c|}{$\mathrm{CH}$} & \multicolumn{2}{|c|}{$\mathrm{S}$} \\
\hline Specific language & $\mathrm{O}$ & $\mathrm{i}$ & $\mathrm{O}$ & $\mathrm{i}$ & $\mathrm{O}$ & $\mathrm{i}$ & $\mathrm{O}$ & $\mathrm{i}$ & $\mathrm{o}$ & $\mathrm{i}$ & $\mathrm{O}$ & $\mathrm{i}$ & $\mathrm{o}$ & $\mathrm{i}$ \\
\hline Spontaneous language & $\mathrm{O}$ & $\mathrm{i}$ & $\mathrm{O}$ & $\mathrm{i}$ & $\mathrm{O}$ & $\mathrm{i}$ & $\mathrm{O}$ & $\mathrm{i}$ & $\mathrm{O}$ & i & $\mathrm{O}$ & $\mathrm{i}$ & $\mathrm{O}$ & $\mathrm{i}$ \\
\hline Dyslalia & \multicolumn{6}{|c|}{ Yes } & \multicolumn{4}{|c|}{ No } & & & & \\
\hline Velopharyngeal deficiency & \multicolumn{6}{|c|}{ Light } & \multicolumn{3}{|c|}{ Moderate } & & \multicolumn{4}{|c|}{ Severe } \\
\hline Nasopharyngeal endoscopy & \multicolumn{6}{|c|}{ Date: } & & & & & & & & \\
\hline
\end{tabular}

\begin{tabular}{|l|c|c|}
\hline \multicolumn{3}{|c|}{ Psychology } \\
\hline Grief & Current & Sealed \\
\hline Family integrat & Yes & No \\
\hline Family dysfunct & Yes & No \\
\hline Parent's image & Positive & Negative \\
\hline Self-image & Positive & Negative \\
\hline Social integration & \multicolumn{2}{|c|}{ E, VG, G, R, B } \\
\hline
\end{tabular}

\begin{tabular}{|c|}
\hline Observations \\
\hline \\
\hline \\
\hline \\
\hline \\
\hline
\end{tabular}

Fig. 8. Patient's registration form

\section{Conclusion}

In this work we developed a mathematical model that makes possible a full description of cleft lip and palate. In all we defined forty one variables with their domains, and thirteen comparison criterion of different nature (Boolean, fuzzy, absolute difference, etc.). The 
model includes, further, the importance of every variable as well as a weight which reflects the complexity of the cleft. Likewise we defined a function to evaluate the similarity between the clefts. The usefulness of having one such function is that allows evaluating the likelihood not only of different patients, but of the same patient in different points in time. Compare, for example, her/his original condition with her/his condition after a given surgical procedure, yielding information to the surgeon relative to the change in the patient and, therefore, the effect in her/his rehabilitation from the surgical point of view. Furthermore, it is possible to compare clefts which present themselves in different palates with different characteristics (unilateral, bilateral).

We present relevant applications in the four clinical specialties that form the multidisciplinary cleft lip and palate team, and show that the result of the similarity between patients was very close to the expected one; as well as the application of voting algorithm classifying 63 patients, with an efficiency of $90 \%$.

It is important to mention that the methodology used in the mathematical modeling of the clinical problem, was successfully used in the evaluation of surgical complexity of cleft, orthodontic and psychology condition and in the evaluation of speaking of patients with this kind of malformations. The method has been of great value for the different specialists, since it allows them to make the description of the patient during their rehabilitation, and enables them to compare the change in the patient's status. With this information they have been able to ascertain the efficacy of the therapy applied to their patients. They have the opportunity to modify or continue the therapeutic strategy. Hence, once again, the usefulness of the mentioned approach in problems associated to the medical practice has been shown. The evaluation doing by the Cleft Palate Team (surgeons, orthodontists, speech therapists and psychologists) of the patient with cleft lip or palate provides an integral approach of the patient condition at any time of the rehabilitation.

\section{References}

Children's Hospital of Wisconsin. Cleft lip and/or palate. Feb 2009, Available from <http://www.chw.org/display/PPF/DocID/35472/Nav/1/router.asp>

Coy K, Spelz M, JonesK. (2002). Facial appearance and attachment in infantswith orofacial clefts: a replication. Cleft Palate-Craniofac J. Vol. 39, pp. 66-72.

Fox VA, Dodd B, Howard D. (2002). Risk factors for speech disorders in children. Int J Lang Commun Dis. Vol. 37, pp. 117-31.

Friede H, Figueroa AA, Naegele ML, Gould HJ, Kay CN, Aduss H. (1986). Craniofacial growth data for cleft lip patients infancy to 6 years of age: potential applications. Am J Orthodont. Vol. 90, pp. 388-409.

Health Ministry of Mexico. (2008). Cleft lip and palate incidence by age. In: Unique Information System for Epidemiology Vigilance, May 2011, Available from: <http://www.dgepi.salud.gob.mx/anuario/html/anuarios.html (In Spanish)

Hodgkinson PT, Brown S, Duncan D, Grant C, McNaughton A, Thomas P, Mattick CR. (2005). Management of children with cleft lip and palate: A review describing the application of multidisciplinary team working in this condition based upon the experiences of a regional cleft lip and palate centre in the united Kingdom. Fetal and Maternal Medicine Review. Vol. 16, No. 1, pp. 1-27. 
Kernahan DA, Stark RB. (1958). A new classification for cleft lip and cleft palate. Plastic Reconstructive Surgery, Vol. 22, pp. 435-439.

Kerr WJ, Miller S, Dawber JE. (1992). Class III malocclusion: surgery or orthodontics? Br J Orthod. Vol. 19, pp. 21-4.

Langlois J. (1995). Infant attractiveness predicts maternal behaviors and attitudes. Dev Psychol. Vol. 31, pp. 464-72.

Martínez-Trinidad JF and Guzmán-Arenas A. (2001). The logical combinatorial approach to pattern recognition, an overview through selected works. Pattern Recognition, Vol. 34, pp. 741-751.

Ortiz-Posadas MR and Lazo-Cortés MS. (2002). A Mathematical Model to Evaluate the Speaking of Patients with Cleft Palate. Proceedings of 2nd European Medical and Biological Engineering Conference. Vienna Austria, September 2002.

Ortiz-Posadas MR, Vega-Alvarado L and Toni B. (2004). A similarity function to evaluate the orthodontic condition in patients with cleft lip and palate. Medical Hypotheses, Vol. 63, No. 1, pp. 35-41.

Ortiz-Posadas MR, Vega-Alvarado L and Toni B. (2009). A Mathematical Function to Evaluate Surgical Complexity of Cleft Lip and Palate. Computer Methods and Programs in Biomedicine, Vol. 94, pp. 232-238.

Parker SE, Mai CT, Canfield MA, Rickard R, Wang Y, Meyer RE, Anderson P, Mason CA, Collins JS, Kirby RS, Correa A. (2010). Updated National Birth Prevalence Estimates for Selected Birth Defects in the United States, 2004-2006. Birth Defects Research Part A: Clinical and Molecular Teratology, Vol. 88, No. 12 (Dec), pp. 1008-16.

Pelchat D, Bisson J, Bois C, Saucier J. (2003). The effects of early relational antecedents and other factors on the parental sensitivity of mothers and fathers. Inf Child Dev. Vol. 12 , pp. $27-51$.

Pruzinsky T. (1992). Social and psychological effects of major craniofacial deformity. Cleft Palate-Craniofac J. Vol. 29, pp. 578-84.

Semb G. (1991). A study of facial growth in patients with unilateral cleft lip and palate treated by the Oslo CLP team. Cleft Palate Craniofac J. Vol. 28, pp. 1-21.

Stellzig-Eisenhauer A, Lux CJ, Schuster G. (2002). Treatment decision in adult patients with Class III malocclusion: orthodontic therapy or orthognathic surgery? Am J Orthod Dentofacial Orthop. Vol. 122, pp. 27-37.

Sze - Van F, Bendeus M, Wing - Kit R. (2007). A multidisciplinary team approach of cleft lip and palate management. Hon Kong Dental Journal, Vol. 4, pp. 38:45.

World Health Organization. (Feb, 2007). Oral Health, Fact sheet No. 318. In: WHO Media Centre. June 2011. Available from <http://www.who.int/mediacentre/factsheets/fs318/en/>

Witzel MA, Salyer KE, Ross RB. (1984). Delayed hard palate closure: the philosophy revisited. Cleft Palate J., Vol. 21, pp. 263-69.

Witzel MA. (1991). Speech evaluation and treatment. Oral Maxillofacial Surgery Clinical North America, Vol. 3, pp. 501-516. 


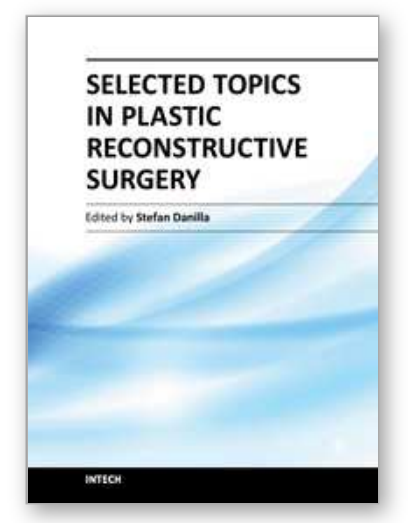

\author{
Selected Topics in Plastic Reconstructive Surgery \\ Edited by Dr Stefan Danilla
}

ISBN 978-953-307-836-6

Hard cover, 242 pages

Publisher InTech

Published online 20, January, 2012

Published in print edition January, 2012

Plastic Surgery is a fast evolving surgical specialty. Although best known for cosmetic procedures, plastic surgery also involves reconstructive and aesthetic procedures, which very often overlap, aiming to restore functionality and normal appearance of organs damaged due to trauma, neoplasm, ageing tissue or iatrogenesis. First reconstructive procedures were described more than 3000 years ago by Indian surgeons that reconstructed nasal deformities caused by nose amputation as a form of punishment. Nowadays, many ancient procedures are still used like the Indian forehead flap for nasal reconstruction, but as with all fields of medicine, the advances in technology and research have dramatically affected reconstructive surgery.

\title{
How to reference
}

In order to correctly reference this scholarly work, feel free to copy and paste the following:

Martha R. Ortiz-Posadas and Leticia Vega-Alvarado (2012). Mathematical Modeling in Rehabilitation of Cleft Lip and Palate, Selected Topics in Plastic Reconstructive Surgery, Dr Stefan Danilla (Ed.), ISBN: 978-953-307836-6, InTech, Available from: http://www.intechopen.com/books/selected-topics-in-plastic-reconstructivesurgery/mathematical-modeling-in-rehabilitation-of-cleft-lip-and-palate

\section{INTECH}

open science | open minds

\section{InTech Europe}

University Campus STeP Ri Slavka Krautzeka 83/A 51000 Rijeka, Croatia Phone: +385 (51) 770447

Fax: +385 (51) 686166 www.intechopen.com

\section{InTech China}

Unit 405, Office Block, Hotel Equatorial Shanghai No.65, Yan An Road (West), Shanghai, 200040, China 中国上海市延安西路65号上海国际贵都大饭店办公楼 405 单元 Phone: +86-21-62489820

Fax: $+86-21-62489821$ 
(C) 2012 The Author(s). Licensee IntechOpen. This is an open access article distributed under the terms of the Creative Commons Attribution 3.0 License, which permits unrestricted use, distribution, and reproduction in any medium, provided the original work is properly cited. 